Article

\title{
Sustainable Aluminium Systems
}

\section{Evangelos Efthymiou $^{1, *}$, Öget N. Cöcen ${ }^{2, \uparrow}$ and Sergio R. Ermolli ${ }^{3}$}

1 Department of Civil Engineering, Institute of Metal Structures, Aristotle University of Thessaloniki, University Campus, Thessaloniki, GR 54124, Greece

2 Faculty of Architecture and Engineering, Yasar University, Yasar University Selcuk Campus 35-37, Bornova, Izmir, PK 35100, Turkey; E-Mail: ogetcocen@gmail.com

3 Department of Urban Design and Planning, Faculty of Architecture, University of Naples Federico II, Via Toledo 402, Naples, 80134, Italy; E-Mail: russermo@unina.it

* Author to whom correspondence should be addressed; E-Mail: vefth@ civil.auth.gr; Tel.: +30-231-0994223; Fax: +30-231-0995642.

$\dagger$ Current Affiliation: Department of Civil Engineering, Institute of Metal Structures, Aristotle University of Thessaloniki, University Campus, Thessaloniki, GR 54124, Greece

Received: 2 August 2010 / Accepted: 2 September 2010 / Published: 17 September 2010

\begin{abstract}
In the present paper, an analytical presentation of some popular aluminium systems that contribute to sustainability of structures is presented. Special emphasis has been given to the properties of aluminium, while the influence of these systems in the overall performance of the structure regarding environment and economy is described. In particular, characteristics of aluminium elements such as high reflectivity and recyclability and their role in life cycle analysis (LCA) are analyzed. The connections between energy efficiency and conservation of buildings and aluminium application are also discussed. Building applications such as curtain walls, window frames and facade sheets are presented and thoroughly investigated, considering their environmental and economic aspects. Furthermore, many innovative techniques that use aluminium elements in collaboration with other systems in order to produce renewable energy, such as solar panels and photovoltaics, are introduced. Finally, environmental innovations such as optimized ventilation mechanisms and light and shade management systems based on aluminium members are presented.
\end{abstract}


Keywords: sustainability; structural aluminium; sustainable constructions; aluminium building systems

\section{Introduction}

As the consequences of environmental impacts have an increasingly negative influence on our daily life, the need for taking immediate measures for the protection of the environment is imperative. There is a global ecological concern being developed and the need for adopting environmentally friendly policies is deeply felt by more and more factors (society, industries, governments, etc.). The climate change, the greenhouse effect and the depletion of the ozone layer are some of the impacts of uncontrolled industrial activities.

The building sector is the biggest consumer of raw materials and energy, and the role of environmental parameters regarding the design and construction of building applications is becoming more significant. In the construction field, building consumes significant amounts of energy, currently about $40 \%$, of the total energy consumption in the member states of the European Union (EU), and contributes about $45 \%$ of the carbon dioxide emissions released in the atmosphere. In this framework, the need to reduce the consumption of fossil sources of energy, to deal with the problem of material flow and waste production and its treatment, is imperative. In recent years, the green building perception has become a popular trend, whereas the necessity to adopt an approach in assessing the impact of building activities on the environment, economy and society, is recognized by all factors in the construction business.

The scope of the present research effort is to focus on environmental perception and to investigate the relationship between sustainability and aluminium building systems. Aluminium is a new constructional material comparable to steel or concrete and can contribute to sustainability of structures, where its physical and mechanical properties can provide buildings a green performance in terms of ecology and economy in addition to providing functionality and structural stability. This paper aims at presenting some of the most commonly used aluminium systems and their special features that contribute to sustainability.

\section{Aluminium in the Construction Industry}

\subsection{Structural Aluminium: The Material}

Lightweight materials such as aluminium offer the construction industry an opportunity to design and manufacture high performance structures that are safe, energy-efficient and environmentally friendly, and much lighter than traditional designs. These materials can be used for a wide range of applications due to potential interactions between the materials, which enables their use in structural design and the manufacturing process. In civil engineering works, aluminium is usually classified as a metal whose basic ingredient is either aluminium or aluminium alloy. Pure aluminium is a metal with a strength varying from $90 \mathrm{~N} / \mathrm{mm}^{2}$ to $140 \mathrm{~N} / \mathrm{mm}^{2}$, for this reason it is reluctantly used for structural 
purposes in construction. However, when it is added to other metals, such as $\mathrm{Mg}$, or with metalloids like $\mathrm{Si}$, aluminium alloys are formed whose strength is high and in some cases can reach up to $500 \mathrm{~N} / \mathrm{mm}^{2}$ [1]. Structural aluminium alloys are classified in various categories with regard to their chemical composition and the processes they are subjected to; every alloy is characterized by unique properties and exhibits different structural behavior. They represent a wide family of constructional materials, whose mechanical properties make them extremely popular in civil engineering works and cover an extended range of application fields.

Regarding aluminum alloys series and their usage in building applications, non heat treatable alloys of 3xxx series such as AW 3103, which are characterized by strength and good corrosion resistance, are mostly used in cladding systems, in facade engineering. Furthermore, alloys of series 5xxx are very corrosion resistant, are suitable for welding, and some of them, for example AW 5083 and AW 5454, are used in special works such as chemical plants and road tankers. The most commonly used series in construction is the 6xxx series, where alloys like AW 6063, AW 6061 and AW 6082 are used in architectural extrusion window frames and roof trusses.

In addition, their physical properties, such as lightness, are advantageous as erection phases can be simplified, reducing the loads transmitted to foundations and the heavy physical labor. Another characteristic of aluminium alloys is their corrosion resistance, which results in reducing maintenance costs and assuring a good performance in highly corrosive environments [2]. It is noteworthy that the functionality of aluminium alloys regarding geometrical shapes can make them highly competitive as the geometrical properties can be improved through the design of sections, as stiffened shapes can be obtained without using built up systems, and as simplifying connecting systems among different structural members, thus improving joint details [3]. Aluminium applications can be both structural and non structural. Regarding structural applications, aluminium alloys are usually used in large span roof systems, where live loads are small compared to dead loads. In addition, they are used in structures located in inaccessible places far from the fabrication shop, thus they can provide transport economy and ease of erection. In structures like swimming pool roofs, harbor elements, and river bridges, which are characterized be humid environments, aluminium alloys are preferable [4].

\subsection{Sustainable Features of Aluminium Alloys}

The concept of "sustainable construction" has been developed, which involves minimizing building costs, materials, waste, energy use, and improving energy efficiency of the structure. Sustainability also includes low operating and maintenance costs, along with creating conditions for healthy, safe and comfortable living. Furthermore, it includes also the choice of recyclable construction materials and products since saving energy is a major objective, and the removal or not of materials at the end of their life cycle is dependent on this choice. In addition, sustainable design means considering the whole lifetime of a structure, investigating ways of reducing the environmental impacts of building activities, importing the assessment of life-cycle costs of buildings, into the primary process. In this framework, techniques and methods of minimizing the release of emission and the consumption of resources in the construction of building products in transport, installation and maintenance during their service life, are also included in the sustainable design. Generally, sustainable building is building where the principles of sustainable development in the construction industry are applied. 
These are to optimize structures according to their individual requirements on three levels simultaneously, namely ecological, economic and socio-cultural [5].

Sustainability in architecture means buildings which combine comfort for the user while respecting the environment and minimum energy usage. Energy performance, user comfort, building functionality and cost over the lifetime of the building are the main objectives. Sustainable buildings emit less "greenhouse" gases and their materials can be infinitely recycled. Aluminium can justifiably be described as the "green metal": it is non-toxic and recyclable, easily formed yet strong, durable yet modern. Large savings in energy usage can be achieved using Aluminium façades, which act as solar reflectors and thermal buffers. An aluminium facade can be integrated into the diversity of the architectural tradition.

From the sustainable point of view, aluminium alloy structures provide excellent credibility when the long-term approach is being adopted. Despite the initial high cost and the great amounts of energy consumption during production, the special features of alloyed aluminium enable sustainable performance when the whole service lifetime of the structure is considered.

To begin with, aluminium building material has a very long life cycle, ranging from 30 to 50 years, and due to this durability, the maintenance costs are very low over the lifetime of the structure. In addition, the majority of alloys used in construction are weather-proof and corrosion resistant, thus a long serviceable lifetime is assured [6]. Another important characteristic of the material is its high reflectivity, which can be exploited in several building techniques and systems. An example of this is the installation of aluminium solar collectors to lower energy consumption for heating in winter and artificial lighting, also aluminium shading devices that reduce the need for air-conditioning in the summer. Furthermore, aluminium alloys exhibit excellent recyclability. Used aluminium products and scrap can be recycled, thus reducing the environmental impact related to waste. As almost all aluminium material used in construction can be recycled, the considerable energy invested in the production of primary aluminium can be reinvested into other aluminium products. Scrap may not necessarily be recycled back into its original product or even reused in the country in which it was first manufactured, but the original energy investment will not be lost.

Concerning structural applications and aluminium alloys, their strength, weight and versatility make them ideal building and cladding materials. Since they are corrosion resistant, they are mostly used in maintenance free applications such as siding, windows, skylights, doors, screens, gutters, down spouts, hardware, canopies and shingles, etc. Regarding aluminium siding, systems are also available with insulation and reflective foil backing, so walls can be made weatherproof and energy-efficient. A layer of insulated aluminium siding is four times more effective than uninsulated wood siding, four inches of brick or ten inches of stone masonry.

In addition, the relatively low melting point $\left(660^{\circ} \mathrm{C}\right)$ of aluminium alloys results in an early heat release and thereby saves lives and property. Regarding recycling, aluminium not only has important economic implications but also contributes to environmental production, whereas depositing or incineration does not have harmful side-effects even if inadvertently dispersed in the environment. 


\subsection{Life Cycle Analysis and Aluminium}

When choosing a material for any application it is important to look at the whole of the product's life cycle. Life cycle analysis, in fact, goes far beyond the production processes alone. The life cycle of aluminium alloys is divided into several stages [7]. In the first phase, design and calculation, various alloys with different characteristics and strength values are considered. According to the type of alloy, high strength values, even within the range of steel, are available. The low material density values of aluminum can reduce the total weight of structures significantly, with savings of up to $50 \%$ of comparable steel sections. Static design and quality control are covered in various standards, currently being further developed and harmonized. The second phase includes the production, transport and assembly. Production of one ton of aluminium requires four tons of bauxite. The subsequent chemical and electrolytic processes consume a rather high amount of energy. For the production of one ton of primary aluminium, currently an average of $15.5 \mathrm{MWh}$, sufficient for the production of five tons of steel, are required. Depending on the product, cross section form and respective energy price, the initial cost is rather high, but may vary widely. Due to its light weight and its high grade of formability aluminium cuts costs, energy and time in transport and erection too. The next stage is the use-service phase. The natural corrosion resistance provides a high level of durability, together with minimum inspection and maintenance requirements. This leads to significant cost and energy savings, especially in comparison to other materials requiring regular painting. Aluminium in the building envelope requires well planned thermal insulation because of its high heat conductivity value $\left(\lambda_{\text {RAlu }}=200 \mathrm{~W} / \mathrm{mk}\right.$, $\left.\lambda_{\text {RAlloy }}=160 \mathrm{~W} / \mathrm{mk}\right)$ compared to other building materials $\left(\lambda_{\text {RGlass }}=0.80 \mathrm{~W} / \mathrm{mk}, \lambda_{\text {RSteel }}=60 \mathrm{~W} / \mathrm{mk}\right)$. The dismantling, transport and recycling procedures are the final phase in the life cycle, as the disposal of a relevant matter, being non-hazardous and of high scrap value.

Aluminium structures are easy to dismantle and transport and the recycling process to produce secondary ingot from scrap requires only $5 \%$ of the input energy required to produce primary aluminium and with no loss in quality. Currently, a recycling rate of $85 \%$ is achieved in the building industry [8]. In total, $6 \%$ of recycled aluminium is reused in building structures. The final phase of a building's life needs to also be considered when making material choices. Ideally the material will be recycled in an economically and environmentally sustainable way. Usually the least desirable option is landfill, whereas a large amount of waste building materials goes to landfill sites at a cost to both the economy and the environment; others are recycled at a cost to the community. In contrast, aluminium is recycled in a way that pays for itself and is sustainable. Aluminium has a low melting temperature and is therefore able to be recycled with comparatively little energy. About $30 \%$ of the world's annual aluminium usage is supplied from processing post-consumer scrap.

\section{Sustainability and Aluminium Systems}

Aluminium can be used for both structural and non-structural applications. Regarding structural applications, aluminium alloys are usually used in large span roof systems, where live loads are small compared to dead loads. In particular, they are often used in structures located in inaccessible places far from the fabrication shop, since they can provide transport economy and ease of erection, which results in cost savings. The lightness of aluminium is a characteristic that contributes to its wide 
structural application and provides many advantages in transportation and erection, especially for prefabricated systems. In addition, in structures like swimming pool roofs, harbor elements, and river bridges, which are characterized by humid environments, the choice of aluminium alloys is preferable [9]. In these cases, due to the corrosion resistance of aluminium alloys, the sustainable feature of durability is achieved and the maintenance costs are less compared to other materials such as steel. In particular, the introduction of the latest version of Eurocode 9, where specifications on the corrosion tendency of aluminium and useful recommendations for selection and protection of aluminium alloys according to various exposure conditions are provided, contributes also to the wide use of aluminium in such structures [10].

Furthermore, the extrusion process of aluminium alloys can improve the geometrical properties of cross-sections in such a way to obtain the minimum weight and the highest structural efficiency. This unique characteristic of fabrication process by extrusion allows individually tailored products to be designed, which provides significant advantages in cases where there are architectural and structural restrictions. In this way efficient and flexible systems can be accomplished which have low environmental impact and require less material use and more economy.

In recent years, the use of aluminium in structural restoration of old suspension pedestrian bridges has become popular. These structures were mostly made of wooden decking, masonry piers, steel structural members (girders and suspension cables) and they were built during the 19th century. In cases where structural consolidation is necessary, aluminium can provide an extremely reliable and effective solution regarding the support of the decking, taking into account its lightness and corrosion resistance [11]. By means of the aluminium application in such cases, the lifetime of the structures is expanded, a lighter solution is promoted, and a structural efficiency of the structure, versatility and flexibility is achieved.. In addition, the aluminium application is more corrosion resistant than steel and the demand for maintenance is less.

In the building sector, the popularity of aluminium alloys in load carrying structures, as well as in secondary or decorative elements, has increased significantly over the past 50 years. Currently, a total of $26 \%$ of all aluminium products is used in building applications [12]. All kinds of aluminium products are used in new home construction and in rehabilitation and renovation of existing structures. The range of building applications of aluminium is wide: it is commonly used in the building envelope for facades, glazed and roofing systems, curtain walling, window frames and doors. Aluminium is also applied for railings, balconies, staircases, heating/ air conditioning and solar elements.

The use of aluminium cladding on building facades is a promising construction alternative for new buildings, where aluminium cladding is placed at a proper distance from the external wall, ranging from 5-10 cm for alignment purposes. The air gap that is created between the building's wall surface and the aluminium cladding, acts as a thermal buffer zone. In particular, curtain walling or roofing can use aluminium with glazing or other transparent and semitransparent materials, creating uninterrupted large surfaces and atriums. Large curtain walling is usually recommended in climates with heating loads (Figure 1). 
Figure 1. Examples of aluminium based curtain-wall applications
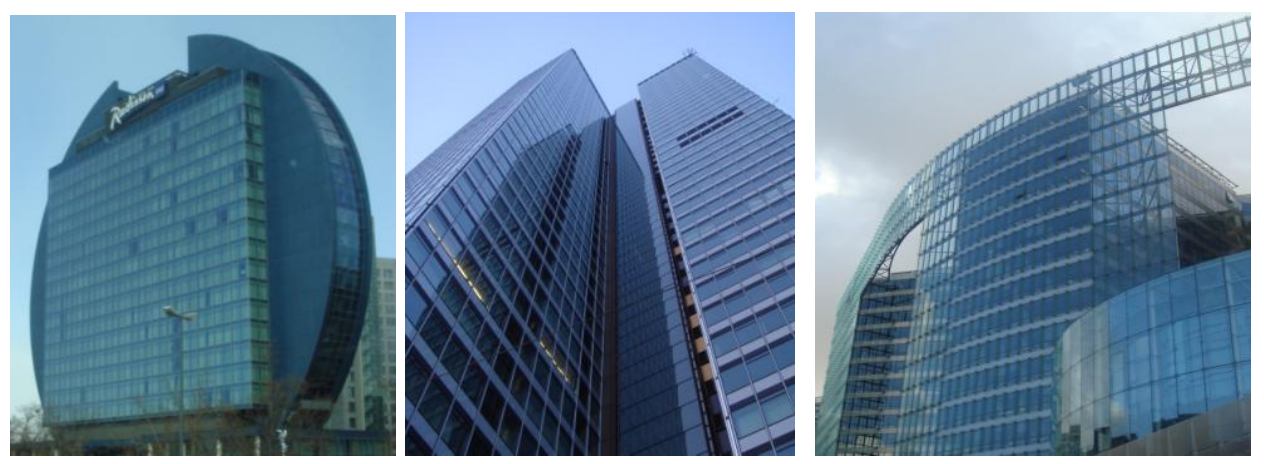

In addition, the use of these systems is very popular for renovation of non-insulated buildings. Aluminium is often used in rehabilitation works as an innovative solution that provides many advantages in restoration activities due to the exploitation of aluminium alloys' special features. Aluminium based cladding systems are durable and achieve high levels of thermal insulation and air tightness regarding external refurbishment of historical building (Figure 2).

Figure 2. Aluminium based cladding system in an historical building.

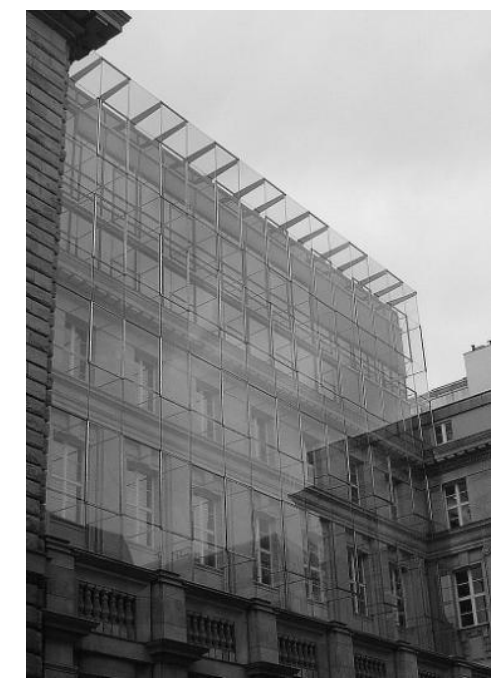

There are also facade and roof systems where aluminium is used in window and glazing frames and glazing spacers. The function of these systems is to provide daylight, visual contact between the exterior and the interior, provide protection against the weather (rain and wind), provide passive solar heating gains, help keep interior thermal comfort, and keep the energy use for operation at a minimum.

In addition, the ventilated facades are complex systems of construction which offer both aesthetic quality and effective insulation, permitting energy savings [13]. This kind of system consists of an outer cladding, an air space at least $40 \mathrm{~mm}$ deep, a sub-structure generally made of aluminium anchored to the building and an insulating layer secured to the outer wall of the building (Figure 3). The main functions of the outer cladding are aesthetic and protective and the air gap is essential for activating the natural ventilation that is necessary for the system to function as a whole. The aluminium sub-structure ensures stability of the cladding system, while the insulating layer, usually consisting of self-supporting water-repellent glass wool panels, takes care of adequate thermal stability. 
These claddings provide an ideal means to achieve an increased energy performance of buildings and to contribute to the improvement of the urban environment.

Figure 3. Schematic of a ventilated façade, consisting of an outer cladding, an air space at least $40 \mathrm{~mm}$ deep, a sub-structure generally made of aluminium anchored to the building and an insulating layer secured to the outer wall of the building

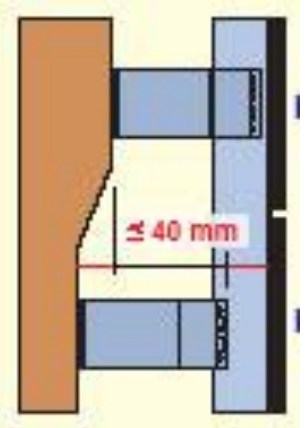

Regarding shading systems, there are venetian blinds, screens, overhangs, sidefins and others. Aluminium is used in lamellas, screens and fins. The function of these systems is to prevent glare and overheating and thereby minimize the energy use for space cooling. A literature survey did not identify any studies dealing with the environmental impacts of such systems that are relevant for this project (Figure 4). There are also day lighting systems, which include devices that enhance the daylight penetration and distribution into the room, e.g., light shelves, light-reflecting lamellas, etc. Better daylight availability and distribution in the space makes it possible to save electricity for artificial lighting, by turning the lights off when there is sufficient daylight. This may also, in turn, reduce the needs for cooling. Aluminium may be used as light directing devices. However, no studies were found that included environmental analysis of such systems.

Figure 4. Shading systems [14].
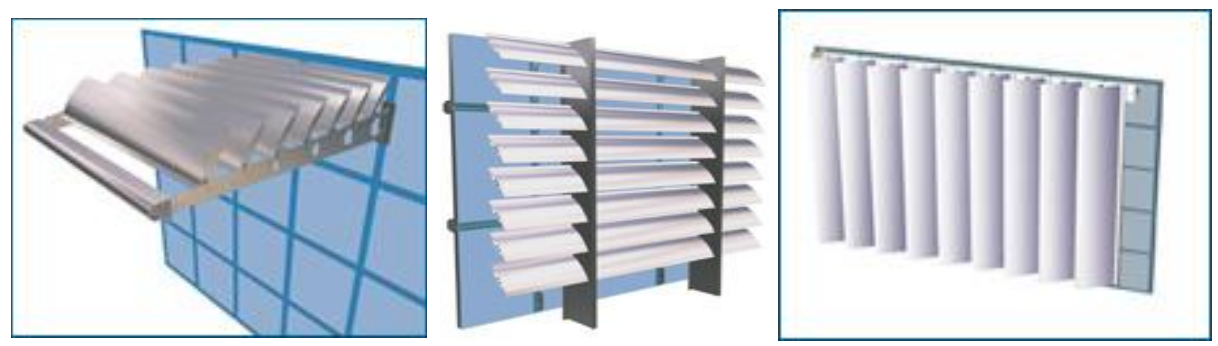

Aluminium is used also in window frames where it provides flexible and popular window geometry and operation. Since aluminium is a good heat conductor, it is necessary to use proper thermal breaks for enhanced thermal performance. Regarding insulation, it offers high levels of heat and noise insulation and the flexible design of systems used in doors and windows enables a choice of traditional or modern structures. Aluminium is a material that does not wear out in time, thus ensuring the longevity of frames. It is also appropriate for areas with high temperatures and intense sunlight. The maintenance and care of frames is quite easy, and they can be cleaned periodically. Aluminium is of 
natural origin, and supply is plentiful. As it is environmental friendly and $100 \%$ recyclable, it does not have a negative effect on human health and the environment.

In places like the Mediterranean, where ample sunlight and wind potential offer plenty of solar and wind power, the exploitation of renewable energy sources is the main objective. The maximum energy from sunlight is produced at peak consumption times and solar energy is converted to a usable form of energy (electricity) through the photovoltaic effect. Photovoltaic Systems in developing countries and isolated areas (e.g., Greek islands) can offer energy solutions and improve the standard of living. The functions of these thermal systems is to provide energy for domestic hot water heating and/or space heating in order to reduce the auxillary energy use (Figure 5). The function of photovoltaic systems is to produce electricity that can be used directly for running lights and equipment in the building or fed into the electric utility grid. In this case, aluminium is used for absorbers, frames and casings for thermal collectors and for frames and support structures for photovoltaic modules.

Figure 5. Photovoltaic systems using aluminium.

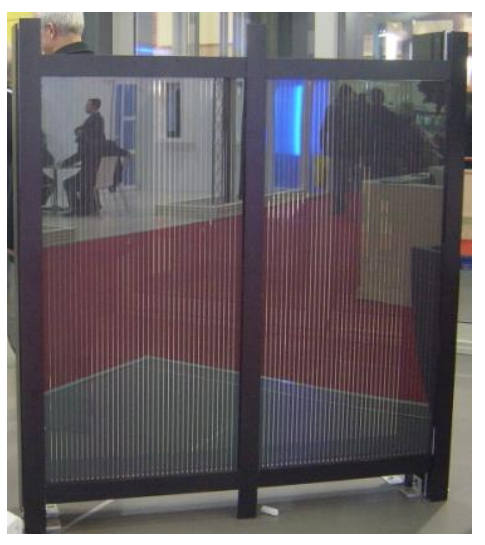

\section{Conclusions and Future Suggestions}

The construction industry is faced with a number of environmental issues ranging from its direct impact on climate change to its choice of materials and its methods of waste disposal. The entire life cycle of a building must be considered when assessing these issues. At the same time, environmental considerations need to be balanced against the realities of design, function and economy. When choosing the optimum material for each building, an approach which takes account of the full lifetime of the material should be adopted, covering construction, use, maintenance and disposal phases. When planning an environmentally sustainable and cost effective building, factors like minimal energy, minimal maintenance, suitability for local climate and minimal waste should be considered.

Nowadays, new building systems and innovative design concepts regarding aluminium alloys cooperating with building elements are adopted in order to provide more sustainable solutions and to meet ecological demands. In particular, facades that incorporate aluminium systems which can decrease energy consumption in buildings by up to $50 \%$ have just started to appear in European constructions. Shading systems, photovoltaic systems, which are aluminium based, are characterized by constructive interaction with the exterior, markedly reducing heating, cooling, ventilation and lighting energy demands. New technologies mean solar power captors can be inserted in aluminium frames, thus saving considerable amounts of energy and protecting the environment. Numerous 
techniques are being adopted and processes need to be verified and tested in order to ensure long-term sustainability and at the same time static stability and fitness.

\section{References}

1. Radlbeck, C.; Dienes, E.; Kosteas, D. Sustainability of Aluminium in Buildings. Struct. Eng. Int. 2004, 3, 221-224.

2. Efthymiou, E. Development of Yield Lines in Aluminium Bolted Joints under Tension. A Numerical and an Experimental Approach; Ph.D. Thesis; Aristotle University of Thessaloniki: Thessaloniki, Greece, 2005.

3. Baniotopoulos, C.C. Structural Metal Connections in the Framework of Eurocodes 3\&9; Ziti Publications: Thessaloniki, Greece, 2003.

4. Mazzolani, F.M. Aluminium Alloy Structures; E\& FN Spon: London, UK, 1995.

5. Kissel, J.R.; Ferry, R.L. Aluminium Structures: A Guide to Their Specifications and Design, 2nd ed,; John Wiley \& Sons: New York, NY, USA, 2002.

6. TALAT "Training in Aluminium Application Technologies"; European Aluminium Association (EAA): Brussels, Belgium, 1999.

7. Life Cycle Assessment of Aluminium: Inventory Data for the Worldwide Primary Aluminium Industry; International Aluminium Institute: London, UK, 2003; Available online: http://www. world-aluminium.org (accessed on 30 July 2007).

8. Maydl, P. Structural Sustainability-The Fourth Dimension? Struct. Eng. Int. 2006, 16, 268-269.

9. Aluminium Structural Design; Mazzolani, F.M., Ed.; CISM International Center for Mechanical Sciences: Udine, Italy, 2003.

10. prEN 1999-1-1, Part 1-1. Design of Aluminum Structures: General Structural Rules; European Committee for Standardisation: Brussels, Belgium, 2006.

11. Mazzolani, F.M. Aluminium Structures in Refurbishment: Case of the Real Ferdinando Bridge on Carigliano River. Struct. Eng. Int. 2006, 16, 352-355.

12. Building; European Aluminium Association (EAA): Brussels, Belgium, 2004; Available online: http://www.eaa.net (accessed on 30 July 2007).

13. Andresen, I.; Thyholt, M.; Geissler, S.; Rappl, B. Sustainable Use of Aluminium in Buildings; SINTEF Civil and Environmental Engineering, Architecture and Building Technology: Trondheim, Norway, 2001.

14. Alumil Homepage. http://www.alumil.com (accessed on 30 July 2007).

(C) 2010 by the authors; licensee MDPI, Basel, Switzerland. This article is an open access article distributed under the terms and conditions of the Creative Commons Attribution license (http://creativecommons.org/licenses/by/3.0/). 